\title{
HELLP syndrome in eclampsia and its impact on maternal and foetal outcome: a study in a tertiary care centre of rural India
}

\author{
Shibram Chattopadhyay ${ }^{1}$, Amitava Pal ${ }^{2}$, Rupali Modak ${ }^{3}$, \\ Tapan Kr. Maity ${ }^{1}$, Shritanu Bhattcharya ${ }^{1}$
}

\author{
${ }^{1}$ Department of Obstetrics \& Gynaecology, NRSMCH, Kolkata, West Bengal, India \\ ${ }^{2}$ Department of Obstetrics \& Gynaecology, Burdwan Medical College, Burdwan, West Bengal, India \\ ${ }^{3}$ Department of Obstetrics \& Gynaecology, R. G. Kar Medical College, Kolkata, West Bengal, India
}

Received: 26 June 2014

Accepted: 5 July 2014

\section{*Correspondence:}

Dr. Shibram Chattopadhyay,

E-mail: shibramchatt@gmail.com

(C) 2014 Chattopadhyay S et al. This is an open-access article distributed under the terms of the Creative Commons Attribution Non-Commercial License, which permits unrestricted non-commercial use, distribution, and reproduction in any medium, provided the original work is properly cited.

\begin{abstract}
Background: Objective of current study was to determine the incidence of HELLP syndrome in patients with eclampsia and its impact on maternal and perinatal outcome.

Methods: The prospective study was conducted in the department of obstetrics and gynaecology, Burdwan medical college, Burdwan on 727 eclamptic mothers, admitted from January 2012 to December 2013. Clinical data and detailed investigations including complete haemogram, liver function tests and relevant investigations for haemolysis were analysed. Statistical analysis was performed using student's t-test and $\chi^{2}$ test where appropriate. All $\mathrm{P}$ values $<0.05$ were considered statistically significant.

Results: The incidence of HELLP syndrome among the women of eclamptic mothers was 7.43\% (54/727). Among 54 patients; abruptio placentae (12.96\%), acute renal failure (11.11\%) and cerebral haemorrhage (11.11\%) were most frequent maternal complications followed by DIC (3.70\%). Maternal and perinatal mortality in HELLP syndrome were $7.40 \%$ and $30.5 \%$ respectively. SGOT level was higher in complete HELLP and it is statistically significant when compared to incomplete variant $(\mathrm{P}<0.0004)$. Complete HELLP syndrome is at increased risk for serious complications when compared to incomplete variety.

Conclusions: Classification of HELLP syndrome cases according to the clinical and laboratory findings can help in the monitoring and treatment of the disease.to improve perinatal outcome without increasing maternal morbidity.
\end{abstract}

Keywords: HELLP syndrome, Maternal outcome, Foetal outcome

\section{INTRODUCTION}

HELLP syndrome is a variant of preeclampsia/eclampsia associated with a high maternal mortality and morbidity. ${ }^{1}$ This syndrome was recognised much earlier, it was first described in 1982 by Weinstein. ${ }^{2}$ HELLP syndrome is defined as haemolysis, elevated liver enzyme (serum $\mathrm{LDH} \geq 600 \mathrm{IU} / \mathrm{L}$, or total bilirubin $\geq 1.2 \mathrm{mg} / \mathrm{dl}$ ), and low platelet count $(\leq 100000$ cells $/ \mu \mathrm{l})$. The incidence is reported approximately $0.1 \%$ of all pregnancies, and 10 $20 \%$ with combined preeclampsia and it occurs normally during the third trimester and progress until delivery. ${ }^{3}$ Patients whose pregnancies are complicated by HELLP syndrome are at higher risk of renal failure, consumptive coagulopathy, abruption placentae, pulmonary and cerebral oedema, sub capsular liver haematoma and shock. ${ }^{4}$ Diagnosis of the complete form of HELLP syndrome requires the presence of all three major components, while partial or incomplete HELLP syndrome consists of only 1 or 2 elements of the triad $(H$ or El or LP). ${ }^{5}$ 
The aim of this study is to evaluate the impact of HELLP syndrome on maternal clinical issues with special focus on diagnosis, maternal complications, timing and routes of delivery. Perinatal morbidity and mortality are also outlined.

\section{METHODS}

The prospective study was conducted in the department of obstetrics and gynaecology, Burdwan medical college, Burdwan, between January 2012 to December, 2013 on all eclamptic mothers. The Tennessee classification system $^{6}$ was used to diagnose complete or partial HELLP syndrome. Complete HELLP syndrome included haemolysis (LDH $\geq 600 \mathrm{IU} / \mathrm{L})$, elevated liver enzymes (SGOT $\geq 70 \mathrm{IU} / \mathrm{L})$ and platelet $\left(\leq 100000 / \mathrm{mm}^{3}\right)$ and designated as group- $\mathrm{B}(\mathrm{n}=9)$ in our study. Partial HELLP syndrome (group $\mathrm{A}, \mathrm{n}=45$ ) was diagnosed if the patient presented with one or two of the above criteria. Demographic variables, such as maternal age, parity, gestational age, complaints at admission if patient is conscious, clinical findings, measurement of blood pressure, antihypertensive drug administration, magnesium sulphate and corticosteroid therapy were evaluated. Routine laboratory tests included liver function tests, complete blood count, coagulation profile and renal function tests. Gestational age was determined according to the last menstrual period or first or early second trimester ultrasonography. Different routes of delivery including indications of caesarean section and type of anaesthesia was recorded. APGAR score at 1 and 5 minutes of new born following delivery, birth weight and perinatal outcome were also noted.

Acute renal failure was diagnosed in the presence of oliguria or anuria associated with elevated serum creatinine levels and diminished creatinine clearance. Pulmonary oedema was diagnosed on the basis of clinical finding and chest radiography. Disseminated intravascular coagulation (DIC) was defined as low platelet count $\left(<100000 / \mathrm{mm}^{3}\right)$, low fibrinogen level $(300$ $\mathrm{mg} / \mathrm{dl})$, prolonged prothrombin time $(\geq 14 \mathrm{~s})$, partial thromboplastin time $(\geq 40 \mathrm{~s})$, and elevated fibrin split products $(>40 \mu \mathrm{g} / \mathrm{dl})$. Intrauterine growth restriction was defined as a birth weight below the $10^{\text {th }}$ percentile for that gestational age.

All cases above 34 weeks of gestation were delivered promptly. Pregnancies below 34 weeks were terminated after corticosteroid therapy if the maternal condition was unstable and foetal well-being tests were non-reassuring. Blood and blood products were used to correct coagulation abnormalities and anaemia as needed.

Perinatal mortality rate was defined as "number of foetal deaths after 22 weeks of gestation + number of neonatal deaths during the first 29 days/1000 birth".

Statistical analysis was performed using student's t-test and $\chi 2$ test where appropriate. All analysis was performed by StatCalc-7 software. All $\mathrm{P}$ values $<0.05$ were considered statistically significant.

\section{RESULTS}

Out of 727 cases of eclampsia pt. (incidence 3.91\%) 54 cases had HELLP syndrome (incidence $7.43 \%$ ). HELLP syndrome was diagnosed in the antepartum and postpartum period in $43(79.63 \%)$ and $11(20.37 \%)$ cases respectively. A group of 45 patients were classified as partial or incomplete HELLP (Group A) and a group of 9 patients were classified as complete HELLP syndrome (Group B).

Table 1 shows the different clinical variables in 54 women with HELLP syndrome by different groups. The maternal age, parity, gestational age was similar between the two groups of HELLP syndrome. There was a significant difference of systolic $(\mathrm{P}<0.0146)$ and diastolic $(\mathrm{P}<0.0001)$ blood pressures between the groups of $\mathrm{A}$ and $\mathrm{B}$.

Table 1: Comparison of clinical characteristics of patients with HELLP syndrome between two groups.

\begin{tabular}{|llll|}
\hline Characteristics & Group A $(\mathbf{n = 4 5})$ & Group B $(\mathrm{n}=9)$ & P \\
\hline Maternal age (years) & $20.022 \pm 1.994$ & $19.556 \pm 0.527$ & 0.1831 \\
\hline Nulliparity & $41(91.11)$ & $8(88.89)$ & 0.8337 \\
\hline SBP $(\mathrm{mm}$ of $\mathrm{Hg})$ & $165 \pm 11.544$ & $178 \pm 12.449$ & $0.0146^{\ddagger}$ \\
\hline DBP (mm of Hg) & $109.511 \pm 11.741$ & $128.888 \pm 7.817$ & $0.0001^{\ddagger}$ \\
\hline GA at admission (weeks) & $35.2 \pm 3.805$ & $35.888 \pm 3.756$ & 0.6257 \\
\hline
\end{tabular}

SBP - Systolic blood pressure, DBP - Diastolic blood pressure, GA-Gestational age; Values are expressed as mean \pm standard deviation, $\mathrm{n}(\%) ;{ }^{\star} \mathrm{P}<0.05$ considered statistically significant

Table 2 summarizes the laboratory findings in these 54 women with HELLP syndrome by groups. All patients had platelet count below $1 \mathrm{lakh} / \mathrm{mm}^{3}$ in group B (Mean \pm $\mathrm{SD}, 57888.89 \pm 7372.999$; range 48000 to $72000 / \mathrm{cu} . \mathrm{mm})$. 
There were statistically significant differences in platelet counts, LDH and SGOT levels between the groups of A and $B$ of HELLP syndrome. In group B HELLP syndrome, the maximal $\mathrm{LDH}$ levels ranged from 15122982 IU/L with a mean of 1558.444 IU/L. For group A, the mean was $854.82 \mathrm{IU} / \mathrm{L}$ (range 108-1610IU/L). Change of SGPT level varied according to the severity of the disease. The mean peak serum of LDH, SGPT and SGOT were significantly higher in group B when compared to group A with HELLP syndrome (Figure 1).

Table 2: Comparison of laboratory characteristics of patients with HELLP syndrome between two groups.

\begin{tabular}{|c|c|c|c|}
\hline Characteristics & Group A (n=45) & Group B (n=9) & $\mathbf{P}$ \\
\hline LDH (IU/L) & $854.82 \pm 350.436$ & $1558.444 \pm 593.152$ & $0.0074^{\dagger}$ \\
\hline SGPT (IU/L) & $93.124 \pm 82.364$ & $134.88 \pm 50.949$ & 0.0608 \\
\hline SGOT (IU/L) & $121.677 \pm 108.154$ & $223 \pm 56.046$ & $0.0004^{\dagger}$ \\
\hline Serum bilirubin (mg/dl) & $1.023 \pm 0.311$ & $1.229 \pm 0.455$ & 0.2283 \\
\hline Serum creatinine $(\mathrm{mg} / \mathrm{dl})$ & $0.925 \pm 0.223$ & $1.157 \pm 0.444$ & 0.1605 \\
\hline \multicolumn{4}{|l|}{ Platelets $<10^{5} / \mathrm{mm}^{3}$} \\
\hline $\mathrm{n}(\%)$ & $37(82.22)$ & $9(100)$ & \multirow{2}{*}{$0.0001^{\dagger}$} \\
\hline Mean \pm SD & $75783.78 \pm 12931.7$ & $57888.89 \pm 7372.999$ & \\
\hline \multicolumn{4}{|l|}{ Proteinuria, n (\%) } \\
\hline Nil & $5(11.11)$ & 0 & \multirow{3}{*}{$0.030^{\dagger}$} \\
\hline $1-2+$ & $26(57.78)$ & $2(22.22)$ & \\
\hline $3-4+$ & $14(31.11)$ & $7(77.78)$ & \\
\hline
\end{tabular}

LDH - Lactic dehydrogenase, SGPT - Serum glutamate - pyruvate transaminase, SGOT - Serum glutamate oxaloacetate

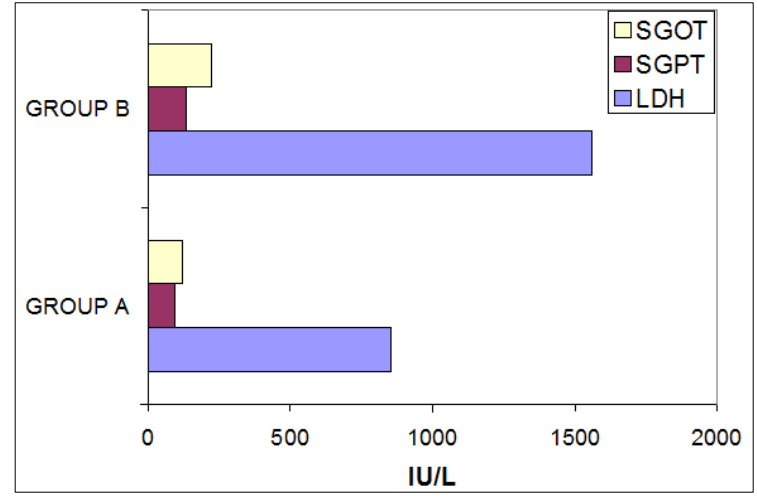

Figure 1: Liver enzymes of HELLP syndrome.

Table 3: Maternal complications in 54 patients with HELLP syndrome.

\begin{tabular}{|l|l|}
\hline Complications & Number (\%) \\
\hline Abruptio placentae & $7(12.96)$ \\
\hline Acute renal failure (ARF) & $6(11.11)$ \\
\hline $\begin{array}{l}\text { Disseminated intravascular } \\
\text { coagulopathy (DIC) }\end{array}$ & $2(3.70)$ \\
\hline Sepsis & $5(9.25)$ \\
\hline Cerebral haemorrhage/infarction & $6(11.11)$ \\
\hline Pulmonary oedema & $5(9.25)$ \\
\hline Maternal death & $4(7.40)$ \\
\hline
\end{tabular}

Data are represented as number/percentage
Table 3 depicts the maternal outcome. Abruptio placentae $(12.96 \%)$, acute renal failure $(11.11 \%)$ and cerebral haemorrhage $(11.11 \%)$ were most frequent maternal complications followed by DIC (3.70\%). Two of the cases of acute renal failure required haemodialysis.

Table 4: Obstetric outcome in 54 patients with HELLP syndrome.

\begin{tabular}{|ll|}
\hline Parameter & Value $(\%)$ \\
\hline Intrauterine growth restriction (IUGR) & $9(16.67)$ \\
\hline Stillbirth & $14(25.92)$ \\
\hline Intrauterine foetal death (IUFD) & 10 \\
\hline Intrapartum foetal death & 4 \\
\hline $\begin{array}{l}\text { Lower segment caesarean section } \\
\text { (LSCS) }\end{array}$ & $15(27.78)$ \\
\hline Birth weight $(\mathrm{g})$ & $2100(700-3250)$ \\
\hline APGAR score $<7$ at $1 \mathrm{~min}$ & $14(25.92)$ \\
\hline APGAR score $<7$ at $5 \mathrm{~min}$ & $5(9.25)$ \\
\hline Foetal distress $* *$ & $5(12.5)$ \\
\hline Neonatal death & $4(7.41)$ \\
\hline
\end{tabular}

Data are presented as median (range) or number/percentage

**The percentage is calculated in patients with alive foetuses in uterus $(n=40)$

Table 4 summarizes the obstetric outcome. Caesarean delivery was noted in $28 \%$ of cases with HELLP syndrome and there was no association between the severity of HELLP syndrome and lower segment 
caesarean section. Indications of caesarean section included foetal distress, malpresentation, previous caesarean section, failed induction, and clinical deterioration of maternal condition. Eleven cases (73.33\%) underwent caesarean section by epidural anaesthesia and the range of platelet count in this group was between $60000-150000 / \mathrm{mm}^{3}$. The 54 eclamptic mothers resulted in 59 births (3 sets of twins and one set of triplets). There were fourteen stillbirths and four neonatal deaths for a perinatal rate of 305 per thousand $(30.5 \%)$.

Comparisons of maternal and foetal morbidity in two groups were enlisted in Table 5. Acute renal failure, intrauterine growth restriction and intrauterine foetal death were statistically significantly higher in group $\mathrm{B}(\mathrm{P}$ $=0.020 ; \mathrm{P}=0.001 ; \mathrm{P}=0.0001)$.

Table 5: Comparison of maternal and foetal outcome in patients with partial (Group A) and complete (Group B) HELLP Syndrome.

\begin{tabular}{|llll|}
\hline $\begin{array}{l}\text { Complications } \\
\text { Abruptio } \\
\text { placenta (7) }\end{array}$ & $\begin{array}{l}\text { Group A } \\
(\mathbf{n}=45)\end{array}$ & $\begin{array}{l}\text { Group B } \\
(\mathbf{n}=9)\end{array}$ & $\mathbf{P}$ \\
\hline DIC (2) & $1(2.22)$ & $3(33.33)$ & 0.046 \\
\hline ARF (6) & $3(6.67)$ & $3(33.33)$ & $0.1970^{*}$ \\
\hline IUGR (9) & $4(8.89)$ & $5(55.56)$ & $0.001^{*}$ \\
\hline IUFD (10) & $3(6.67)$ & $7(77.78)$ & $0.0001^{*}$ \\
\hline $\begin{array}{l}\text { Maternal } \\
\text { mortality (4) }\end{array}$ & $2(4.44)$ & $2(22.22)$ & 0.065 \\
\hline
\end{tabular}

DIC - Disseminated intravascular coagulation, ARF - Acute renal failure, IUGR - Intrauterine growth restriction, IUFD Intrauterine foetal death, data is represented as number / percentage. Statistical analysis was done using Chi-square $\left(\chi^{2}\right)$ test and $* \mathrm{P}<0.05$ considered statistically significant

\section{DISCUSSION}

In our study the incidence of HELLP syndrome in eclamptic mother was $7.43 \%$ where as a high and significant association (36\%) between eclampsia and HELLP syndrome was observed by Vigil-De Gracia $\mathrm{P},{ }^{4}$ but a weak association between HELLP syndrome and eclampsia was noted by Sibai et al. ${ }^{7}$ In our series, most of the HELLP syndrome mothers were nulliparous $90 \%$ $(49 / 54)$ and mean maternal age was $19.944 \pm 1.836$ years. Patients of our series with HELLP syndrome were 5-6 years younger than those reported by other studies. ${ }^{2,4,7}$ It is important that HELLP syndrome is a life-threatening complication of pregnancy associated with hypertension with proteinuria. However severe hypertension and proteinuria were not always associated with the syndrome. ${ }^{4}$ Thirteen percent $(7 / 54)$ of patients in the current study had diastolic $\mathrm{BP} \leq 90 \mathrm{~mm}$ of $\mathrm{Hg}$, which is comparable to the figure $(15 \%)$ in other studies. $2,4,5,7$ Furthermore, the level of proteinuria was variable: 21 women (38.89\%) had proteinuria 3-4+; 28 had 1-2+; and $11.11 \%$ had no proteinuria.

In other series, $6(13.6 \%)$ of the patients were normotensive and 7 (15.9\%) of them had no proteinuria. ${ }^{8}$ So professional care should be taken to all women for HELLP syndrome where hypertension and proteinuria may be absent or slight. In our series $20.38 \%$ of patients had postpartum eclampsia, which is in accordance with the report $(22.8 \%)$ of Yucesoy G et al. ${ }^{8}$

Various maternal complications observed in the present study included abruption placenta, acute renal failure, and placental abruption which are already observed in other studies. ${ }^{9,10,12}$ The overall maternal mortality in our series was $7.40 \%$. The incidence of perinatal mortality was $305 / 1000(30.5 \%)$. The high perinatal mortality is mainly due to delayed referral of patients in the tertiary centre. Perinatal morbidity and mortality cases are still high in HELLP syndrome cases. ${ }^{4,8}$ The current study also demonstrated that the complete HELLP syndrome has an increased risk of maternal outcome.

The vaginal route of delivery is usually recommended to reduce the risk of surgical stress and bleeding during caesarean section. In our series the rate of caesarean section was lower $(27.78 \%)$ when compared to other studies. ${ }^{4,11}$ Epidural anaesthesia is contraindicated in HELLP patients due to risk of developing epidural or subdural haematoma or bleeding. ${ }^{12}$ Eleven patients $(73.33 \%)$ in the current study received epidural anaesthesia without any complication during the procedure. Similar finding was also noted by Vigil-De Gracia P. ${ }^{4}$

\section{CONCLUSION}

The incidence of HELLP syndrome is $7.43 \%$ in pregnancies complicated by eclampsia. Placental abruption, acute renal failure and DIC complicate pregnancies with HELLP syndrome. Perinatal outcome is also adversely affected and mortality rate is $30.5 \%$. To avoid any subsequent complications and to improve the maternal and perinatal outcomes early diagnosis, appropriate and immediate interventions are needed in a tertiary care centre.

\section{ACKNOWLEDGEMENTS}

We are grateful to the principal and medical superintendent cum vice principal of Burdwan medical college and hospital for permission to conduct the study in the department of obstetrics and gynaecology.

Funding: No funding sources

Conflict of interest: None declared

Ethical approval: Not required 


\section{REFERENCES}

1. Kawabata I, Nakai A, Takeshita T. Prediction of HELLP syndrome with assessment of maternal dual hepatic blood supply by using Doppler ultrasound. Arch Gynaecol Obstet. 2006;274:303-9.

2. Weinstein L. Syndrome of haemolysis, elevated liver enzymes, and low platelet count: a severe consequence of hypertension. Am J Obstet Gynaecol. 1982;142:159-67.

3. Ott J, Poschalko, Zeisler H. Severe early onset haemolysis, elevated liver enzyme, and low platelet syndrome in 2 subsequent pregnancies: case report and review of the literature. Arch Gynaecol Obstet. 2010;281:265-8.

4. Vigil-De Gracia P. Pregnancy complicated by preeclampsia-eclampsia with HELLP syndrome. Int $\mathrm{J}$ Obstet Gynaecol. 2001;72:17-23.

5. Barton JR, Sibai BM. Diagnosis and management of haemolysis, elevated liver enzyme, and low platelets syndrome. Clin Perinatol. 2004;31:807-33.

6. Pokharel SM, Chattopadhyay SK, Jaiswal R, Shakya P. HELLP syndrome: a pregnancy disorder with poor prognosis. J Nepal Med Coll. 2008;10:260-3.

7. Sibai BM. Maternal morbidity and mortality in 442 pregnancies with haemolysis elevated liver enzyme, and low platelets (HELLP Syndrome). Am J Obstet Gynaecol. 1993;169:1000-6.
8. Yucesoy G, Yigit C, Bodur H, OzkanS, Tan T. An analysis of HELLP syndrome cases: does platelet count predict adverse maternal and fetal outcome in women with HELLP syndrome? Arch Gynaecol Obstet. 2011;283:941-5.

9. Banoo S, Makhdoomi TA, Mir S, Malik JA. Incidence of HELLP syndrome in severe pregnancy induced hypertension and its impact on maternal and fetal outcome. JK Practitioner. 2007;14:92-4.

10. Audibert F, Friedman SA, Frangieh AY, Sibai BM. Clinical utility of strict diagnostic criteria for the HELLP (haemolysis, elevated liver enzymes, and low platelets) syndrome. Am J Obstet Gynaecol. 1996;175:460-4.

11. Young-quing W, Jing W, Rong-hua YE, Yang-yu Z. Investigation of diagnosis and treatment of haemolysis-elevated liver enzyme-low platelet counts (HELLP syndrome: clinical analysis 59 cases. Chinese Med J. 2010;123:1273-7.

12. Sibai BM. Diagnosis, controversies, and management of the syndrome of haemolysis, elevated liver enzymes, and low platelet count. Obstet Gynaecol. 2004;103:981-91.

DOI: $10.5455 / 2320-1770 . i j r \operatorname{cog} 20140939$

Cite this article as: Chattopadhyay S, Pal A, Modak R, Maity TK, Bhattcharya S. HELLP syndrome in eclampsia and its impact on maternal and foetal outcome: a study in a tertiary care centre of rural India. Int J Reprod Contracept Obstet Gynecol 2014;3:610-4. 